\title{
Initial Oxidation and Subsequent Desulphation of Propan-2-yl Sulphate by Pseudomonas syringae Strain GG
}

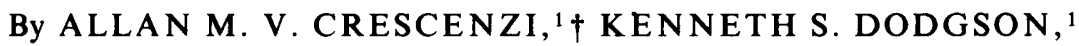 \\ GRAHAM F. WHITE ${ }^{1 *}$ AND WILLIAM J. PAYNE ${ }^{2}$ \\ ${ }^{\prime}$ Department of Biochemistry, University College Cardiff, PO Box 78, Cardiff CFI IXL, UK \\ 2 Department of Microbiology, University of Georgia, Athens, Georgia 30602, USA
}

(Received 2 October 1984)

\begin{abstract}
A strain of Pseudomonas syringae was isolated from garden soil for its ability to utilize propan2-yl sulphate as sole source of carbon and energy. Growth was accompanied by disappearance of the ester from culture fluids and formation of stoicheiometric amounts of inorganic sulphate. However, enzyme activity capable of desulphating propan-2-yl sulphate was not detected under a wide range of assay conditions, either intracellular or extracellular, or at different phases of batch culture. No organic radioactive metabolites were detected during growth on propan-2-yl $\left.{ }^{35} \mathrm{~S}\right]$ sulphate or $\left[1,3-{ }^{1+} \mathrm{C}\right]$ propan-2-yl sulphate alone, but when the latter compound was supplemented with unlabelled lactate, small amounts of ${ }^{14} \mathrm{C}$-labelled lactate were detected. This and the induction by propan-2-yl sulphate of a specific D-lactate-2-sulphatase led to a proposed pathway in which propan-2-yl sulphate undergoes a stereospecific oxidation to D-lactate-2sulphate before rapid desulphation to D-lactate and inorganic sulphate.
\end{abstract}

\section{INTRODUCTION}

Previous studies have shown that the microbial degradation of primary and secondary alkyl sulphate esters begins with liberation of inorganic sulphate by alkylsulphatase enzymes. Primary alkylsulphatases active towards such compounds as sodium dodecyl sulphate (SDS) are widespread (Dodgson, et al., 1982; White et al., 1984) and produce primary alcohols that are further metabolized by oxidation to carboxylic acids and subsequent $\beta$-oxidation. Degradation of secondary alkyl sulphates such as alkan-2-yl sulphates and symmetrical esters also requires initial separation of inorganic sulphate, in this case by stereospecific secondary alkylsulphatases such as those present in Pseudomonas C12B and Comamonas terrigena (Dodgson et al., 1982; Dodgson \& White, 1983). Subsequent oxidation of the liberated secondary alcohol is achieved by stereospecific alcohol dehydrogenases (Barrett et al., 1980, 1981). The resulting ketones are in turn metabolized by a more complicated pathway that leads to $\mathrm{C}-\mathrm{C}$ bond cleavage and generates simple carboxylic acids (Lijmbach \& Brinkhuis, 1973; Dodgson \& White, 1983) suitable for $\beta$-oxidation. Several of the alkylsulphatases that initiate these processes have now been purified and characterized (Cloves et al., 1980; Bartholomew et al., 1978; Matcham et al., 1977; Shaw et al., 1980). More recently a river-mud isolate has been shown to grow well both aerobically and anaerobically on primary alkyl sulphates of chain length $\mathrm{C}_{6}-\mathrm{C}_{12}$, but not on the shorter homologues (Dodgson et al., 1984). Aerobic or anaerobic growth on SDS elicited an inducible primary alkylsulphatase active towards the same esters that supported growth. A common feature emerging from all these studies is the inability of the enzymes to act on alkyl sulphates of chain-length less than about $\mathrm{C}_{5}$, despite the fact that such compounds are known to be present in the environment. For example, the allantois of the developing hen's egg

† Present address: Brewing Research Foundation Research Establishment, Lyttel Hall, Redhill, Surrey RHI 4HY, UK. 
accumulates propan-2-yl sulphate (Yagi, 1964, 1966); fly-ash from coal-burning power stations contains methyl sulphate (Lee et al., 1980); mammals excrete butyric acid-4-sulphate and related compounds as end products of the metabolism of long-chain alkyl sulphates (Denner et al., 1969; Maggs et al., 1982, 1984). Hitherto there have been no reports concerning the microbial degradation of these short-chain sulphate esters. The present paper describes the isolation of a soil bacterium that degrades the short-chain ester, propan-2-yl sulphate, by a novel pathway involving initial oxidation to lactate-2-sulphate followed by hydrolysis to sulphate and D-lactate. The purification and properties of the D-lactate-2-sulphatase that catalyses the latter step have already been reported (Crescenzi et al., 1984).

\section{METHODS}

Unless stated otherwise, all chemicals were the purest available from Sigma or BDH.

Chemical analyses. Potassium contents of sulphate esters were measured by flame photometry in an EEL flame photometer (Evans Electroselenium, Halstead, UK) with $\mathrm{KCl}$ as standard. Ester sulphate contents were measured gravimetrically by conversion to $\mathrm{BaSO}_{4}$ as described previously (White et al., 1980). Elemental analyses for $\mathrm{C}$ and $\mathrm{H}$ contents were performed using a Technicon $\mathrm{CHN}$ Autoanalyser standardized with acetanilide.

Spectroscopic analysis. Infrared spectra of samples incorporated in Nujol mulls, or in $\mathrm{KBr}$ disks, were obtained using a Perkin Elmer Infracord 137 spectrometer. For NMR spectroscopy, samples (15-25 mg) were dissolved in ${ }^{2} \mathrm{H}_{2} \mathrm{O}(0.5 \mathrm{ml}, 99.8$ atom \% excess; Fluorochem, Glossop, UK) and spectra determined using a Perkin Elmer R32 spectrometer operated at $60 \mathrm{MHz}$.

Thin-layer chromatography. For one dimensional chromatography, plastic plates (Merck) coated with silica gel $(0.2 \mathrm{~mm}$ thickness) were cut to $10 \mathrm{~cm}$ (in the direction of elution) $\times 3-20 \mathrm{~cm}$ (depending on the number of samples to be applied). Samples containing 50-200 Bq of radioactive material were applied $1.5 \mathrm{~cm}$ from one edge and plates developed in standard TLC tanks (Shandon Southern Instruments, Camberley, UK) containing one of the following solvents: A, $n$-butanol/acetic acid/water $(50: 12: 25$, by vol. $) ; \mathrm{B}$, propan-2-ol/water $(7: 3, \mathrm{v} / \mathrm{v})$; C, propan2-ol/ammonia (0.880 sp. gr.) $(7: 3, \mathrm{v} / \mathrm{v}) ; \mathrm{D}$, chloroform/methanol/water $(8: 5: 1$, by vol.); E, ethanol/water/ammonia ( $0.880 \mathrm{sp}$. gr.) $(78: 9 \cdot 5: 12 \cdot 5$, by vol.); F, $n$-butanol/acetic acid/ammonia (0.880 sp. gr.) $(4: 1: 1$, by vol.). For two-dimensional chromatography each plate was cut to $10 \times 10 \mathrm{~cm}$ and a sample applied in one corner, $1.5 \mathrm{~cm}$ from adjacent edges. After developing in the first direction, plates were dried at $80^{\circ} \mathrm{C}$ for at least $4 \mathrm{~h}$ before running in the second direction. The two solvent combinations employed were A followed by $\mathrm{C}$, and $\mathrm{B}$ followed by E. Autoradiograms of chromatograms containing radioactive material were produced by exposure of the plates to Kodak X-ray film NS-2T for 1-7 d depending on the amount of radioactivity on each plate. Radioactive areas on chromatograms were located by comparison with the autoradiograms and scraped into scintillation vial inserts containing $0.4 \mathrm{ml}$ of water. Scintillation cocktail $(4.5 \mathrm{ml}$, containing $0.4 \% 2,5$-diphenyloxazole in toluene/Triton $\mathrm{X}-100,2: 1, \mathrm{v} / \mathrm{v}$ ) was added and samples counted using an Intertechnique scintillation counter model SL4041. Quench corrections were made using the external standard-channels ratio method.

Sulphate esters. Unlabelled potassium propan-2-yl sulphate prepared by the method of Lloyd et al. (1961) scaled up 50-fold, gave the following analysis: C, found $21.61 \%$ (theoretical $20.20 \%) ; \mathrm{H}, 3.91 \%(3.93 \%) ; \mathrm{K}, 21.2 \%$ $(21.9 \%) ; \mathrm{SO}_{4}, 54.7 \%(53.9 \%)$. The infrared absorption spectrum was identical to that observed previously (Lloyd $e t$ al., 1961) and the NMR spectrum contained the expected strong doublet $\left[\delta\right.$ (p.p.m.) $\left({ }^{2} \mathrm{H}_{2} \mathrm{O}\right) 1.5(6 \mathrm{H}, \mathrm{d}, J 4 \mathrm{~Hz}$, $\mathrm{CH}_{3} \cdot \mathrm{CH} \cdot \mathrm{CH}_{3}$ )]. The $\mathrm{CH}_{3} \cdot \mathrm{CH} . \mathrm{CH}_{3}$ signal was shifted downfield as expected (White et al., 1980) and was obscured by the ' $\mathrm{H}^{2} \mathrm{HO}$ resonance. Potassium $\left[1,3-1^{4} \mathrm{C}\right]$ propan-2-yl sulphate was prepared by sulphation of the parent alcohol (4 mmol, $1.85 \mathrm{GBq} \mathrm{mol}^{-1}$, Amersham) according to the method of White et al. (1980). The yield was $43 \%$ and the infrared spectrum of the product was identical with that of unlabelled propan-2-yl sulphate. Radiochemical purity was established by TLC in solvents A-F. A single labelled compound was present which had the same $R_{F}$ values as unlabelled propan-2-yl sulphate in all the solvents (A, $0.59 ; \mathrm{B}, 0.75 ; \mathrm{C}, 0.68 ; \mathrm{D}, 0.84 ; \mathrm{E}$, $0 \cdot 72 ; \mathrm{F}, 0.38$ ). The labelled ester also co-chromatographed with authentic unlabelled propan-2-yl sulphate in two different two-dimensional systems (A/C and B/E).

Potassium propan-2-yl $\left.{ }^{35} \mathrm{~S}\right]$ sulphate was prepared by sulphation of propan-2-ol with triethylamine- $N$ $\left[{ }^{35} \mathrm{~S}\right]$ sulphonic acid (kindly provided by Mrs V. Lillis of the Cardiff laboratory) by the method of White et al. (1980). The product had a specific activity of $0.78 \mathrm{GBq} \mathrm{mol}^{-1}$ and was also radiochemically pure according to the chromatographic criteria mentioned above.

D-, L- and DL-Lactate-2-sulphates were prepared and characterized as described previously (Crescenzi et al., 1984).

Sodium DL- $\left[1^{-1+} \mathrm{C}\right]$ lactate $\left(2 \mathrm{TBq} \mathrm{mol}^{-1}\right)$ for use as a TLC standard was the product of Amersham.

Culture media. Carbon sources other than propan-2-yl sulphate were added before autoclaving to a basal salts medium containing $\mathrm{K}_{2} \mathrm{HPO}_{4}, 3.5 \mathrm{~g} ; \mathrm{KH}_{2} \mathrm{PO}_{4}, 1.5 \mathrm{~g} ; \mathrm{NH}_{4} \mathrm{Cl}, 0.5 \mathrm{~g} ; \mathrm{NaCl}, 0.5 \mathrm{~g} ; \mathrm{MgCl}_{2} .6 \mathrm{H}_{2} \mathrm{O}, 0 \cdot 15 \mathrm{~g} ; \mathrm{Na}_{2} \mathrm{SO}_{4}$, $0.14 \mathrm{~g}$ in 1 litre of distilled water. When propan-2-yl sulphate was employed as carbon source in batch cultures, the 
ester solution was sterilized by Millipore filtration and added to sterile basal salts medium lacking $\mathrm{Na}_{2} \mathrm{SO}_{4}$ and in which the concentrations of $\mathrm{K}_{2} \mathrm{HPO}_{4}$ and $\mathrm{KH}_{2} \mathrm{PO}_{4}$ had been doubled ('double phosphate basal salts'). The latter precaution was necessary to compensate adequately for $\mathrm{H}^{+}$formation that occurs concomitantly and stoicheiometrically with liberation of $\mathrm{SO}_{4}^{2-}$. For the preparation of plates and slopes, the basal salts/propan-2-yl sulphate medium was solidified with $1.5 \%$ Noble agar (Difco). Nutrient broth $(0 \cdot 8 \%)$ and nutrient agar $(2 \cdot 3 \%$, $w / v$ ) were prepared according to the manufacturer's (Difco) instructions.

Isolation and identification of bacterium. Garden soil loosely packed in a glass column $(2.5 \times 15 \mathrm{~cm})$ was percolated ( 1 drop every $2 \mathrm{~min}$ ) for $4 \mathrm{~d}$ at room temperature with basal salts containing $0.05 \%$ propan-2-yl sulphate. Subsequently, the concentration of ester was increased at $4-\mathrm{d}$ intervals to $0 \cdot 1 \%, 0 \cdot 15 \%, 0 \cdot 2 \%$ and $0 \cdot 3 \%$. Final eluates from the column were used to inoculate sterile tubes containing $6 \mathrm{ml}$ of basal salts $/ 0 \cdot 3 \%$ propan- 2 -yl sulphate medium. When growth occurred, transfers were made to fresh medium $(20 \mathrm{ml})$ which was then shaken at 120 r.p.m. and $20^{\circ} \mathrm{C}$ until extensive growth had occurred $\left(\mathrm{OD}_{420}>1 \cdot 0\right)$. After four subsequent subculturings, the medium was plated out on nutrient agar and on Noble agar containing $0.3 \%$ propan-2-yl sulphate. A single colony morphology was evident, and after three successive transfers on each solid medium, the organism was transferred back to basal salts $/ 0.3 \%$ propan-2-yl sulphate liquid medium to ensure that it had retained the ability to grow on the ester. Successive transfers on nutrient agar over several months did not lead to loss of ability to degrade propan2 -yl sulphate and the organism was subsequently maintained on nutrient agar alone. The bacterium was characterized at the Torry Research Station, Aberdeen, UK, as an oxidase-negative, green fluorescent, flagellated pseudomonad with properties corresponding (Doudoroff \& Palleroni, 1974) to those of Pseudomonas syringae. It was accordingly so identified and designated as strain GG.

Culture conditions. Bacteria were grown at $20^{\circ} \mathrm{C}$ in batch culture in Erlenmeyer flasks ( $50 \mathrm{ml}$ to 21 capacity) shaken at 120 r.p.m. Inocula were prepared by aseptic transfers from nutrient agar stock slopes or plates to $20 \mathrm{ml}$ of medium to be used. The starter cultures were incubated until mid- to late-exponential phase, and used to inoculate the main flasks. Inoculum sizes were $1 \%$ for growth on propan-2-yl sulphate and $0.5 \%$ for other carbon sources. Bacterial growth was monitored by optical density of the cultures at $420 \mathrm{~nm}$ for defined media and $650 \mathrm{~nm}$ for nutrient broth cultures in a Cecil digital UV spectrophotometer, model no. CE 292.

Preparation of cell extracts. Cells were harvested by centrifugation $(31000 \mathrm{~g}$ for $30 \mathrm{~min})$, resuspended in cold $10 \mathrm{~mm}$-Tris/ $\mathrm{HCl}, \mathrm{pH} 7.5$ ( $2 \%$ of the original culture volume) and disrupted by passage through a chilled French pressure cell (Aminco, American Instrument Co., Silver Springs, Md, USA) operating at $120 \mathrm{MPa}$. Alternatively cells were ruptured by sonicating for $5 \mathrm{~min}$ at $0{ }^{\circ} \mathrm{C}$ using a Sonifier Cell Disrupter Model B-30 (Branson Sonic Power Company, Danbury, Conn., USA) operating at $20 \mathrm{~Hz}$ and $90 \mathrm{~W}$ in the pulsed mode ( $1 \mathrm{~s}$ cycle, $50 \%$ duty cycle). Unbroken cells and cell debris were removed by centrifugation $\left(40000 \mathrm{~g}_{\mathrm{as}}\right.$ for $1 \mathrm{~h}$ at $\left.4{ }^{\circ} \mathrm{C}\right)$. When necessary, extracts were dialysed against $50 \mathrm{~mm}-\mathrm{Tris} / \mathrm{HCl}, \mathrm{pH} 7.5$.

Protein assa.js. Protein concentrations were determined by the method of Lowry using bovine serum albumin as standard.

Assays for sulphatase activity. The search for the ability to hydrolyse propan-2-yl sulphate was made by incubating the ester with various cell extracts, and measuring any enzymically liberated sulphate. Propan-2-yl sulphate $(100 \mu \mathrm{l}$ of $20 \mathrm{mM}$ in $0.1 \mathrm{M}$-Tris $/ \mathrm{HCl}, \mathrm{pH} 7.5)$ was incubated with an equal volume of cell extract or concentrated culture medium at $25^{\circ} \mathrm{C}$. After an appropriate interval, the reaction was stopped by addition of $50 \mu \mathrm{l}$ $15 \%(w / v)$ trichloroacetic acid. Precipitated protein was removed by centrifugation (MSE Centaur 2) and $200 \mu 1$ of clear supernatant was analysed for $\mathrm{SO}_{4}^{2-}$ content by the $\mathrm{BaCl}_{2}$ /gelatin method of Dodgson (1961) as modified by Thomas \& Tudball (1967). To reduce the possibility of missing the activity by use of inappropriate assay conditions, the three most critical parameters (substrate concentration, $\mathrm{pH}$ and temperature) in the standard assay were varied, one at a time, through the following values: final substrate concentration $0.5,1 \cdot 0,2 \cdot 5,5 \cdot 0$ and $10.0 \mathrm{~mm} ; \mathrm{pH} 6 \cdot 0,7 \cdot 5$ and $8 \cdot 5$; temperature 20,25 and $30^{\circ} \mathrm{C}$.

Lactate-2-sulphatase activity was measured in a similar way, employing $20 \mathrm{~mm}$-DL-lactate-2-sulphate as substrate in $0.1 \mathrm{M}$-Tris $/ \mathrm{HCl}, \mathrm{pH} 7 \cdot 5$, at $25^{\circ} \mathrm{C}$, with incubation periods up to $30 \mathrm{~min}$.

\section{RESULTS}

\section{Growth characteristics}

$P$. syringae strain GG grew well and reproducibly on nutrient broth and basal salts/pyruvate $(1 \%$ ), with doubling times of $1.7 \mathrm{~h}$ and $1.3 \mathrm{~h}$, respectively (Fig. $1 \mathrm{a}$ ). Growth on propan-2-yl sulphate in double phosphate basal salts was also good, provided that the volume of the inoculum was at least $1 \%$ of the total culture volume. With smaller inocula, growth curves were irreproducible. Fastest doubling times (about $3 \mathrm{~h}$ ) were achieved at or above $0 \cdot 3 \%$ propan-2-yl sulphate, and the ester was growth-limiting below $0.75 \%$ (Fig. $1 \mathrm{~b}$ ). 


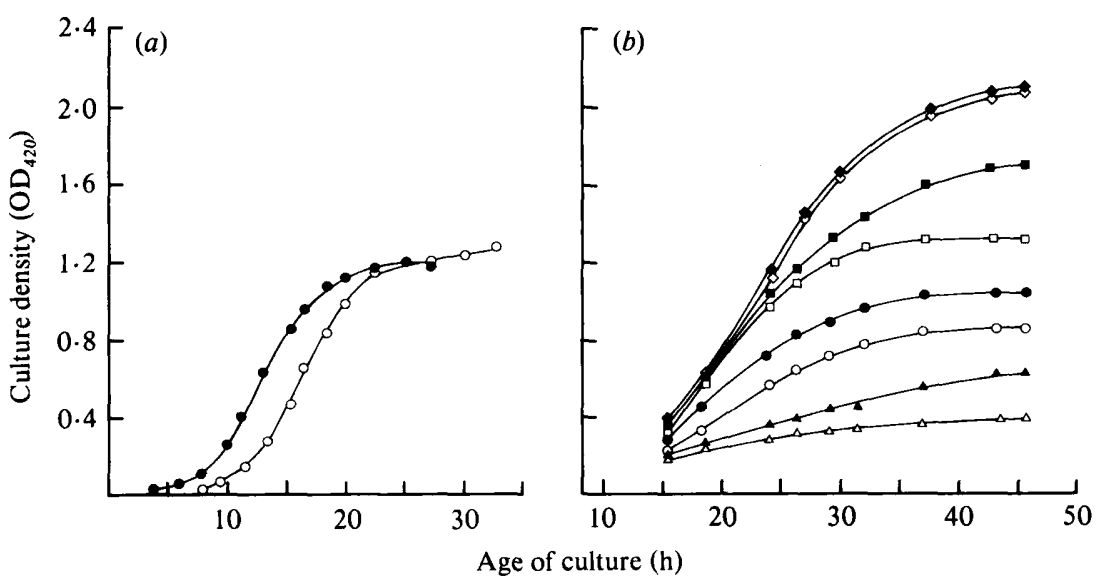

Fig. 1. Growth curves for $P$. syringae in batch culture. (a) Growth on $0.8 \%$ nutrient broth $(\bullet)$ and $0.3 \%$ pyruvate $(O)$. (b) Growth on $0.05 \%(\triangle), 0.10 \%(\Delta), 0.15 \%(O), 0.2 \%(\bullet), 0.3 \%(\square), 0.5 \%(\square), 0.75 \%$ $(\diamond)$ and $1.0 \%(\diamond)$ propan-2-yl sulphate as sole source of carbon and energy. OD values above 1.2 were estimated by diluting cultures before measurement and multiplying the result by the dilution factor.

\section{Attempts to detect sulphatase activity towards propan-2-yl sulphate}

Degradation of alkyl sulphates in micro-organisms usually proceeds via desulphation of the ester by the action of a sulphatase followed by subsequent oxidation and metabolism of the resulting alcohol. It therefore seemed reasonable to suspect that $P$. syringae GG would produce a sulphatase to enable it to initiate degradation of propan-2-yl sulphate. The bacterium was grown to the stationary phase on 101 double phosphate basal salts containing $0 \cdot 3 \%(\mathrm{w} / \mathrm{v})$ potassium propan-2-yl sulphate. Cells were harvested, resuspended in $0.5 \mathrm{M}-\mathrm{NaCl}(100 \mathrm{ml})$, stirred for $30 \mathrm{~min}$ and centrifuged again. The pellet was resuspended in $50 \mathrm{~mm}-\mathrm{Tris} / \mathrm{HCl}, \mathrm{pH} 7 \cdot 5$, and the suspension divided into two portions. One portion of cells was disrupted by passage (four times) through a French pressure cell, and the other by sonication. Each lysate was sub-divided into two portions, one of each pair being stored untreated, and the other being centrifuged $\left(30000 \mathrm{~g}_{\mathrm{av}}\right.$. for $60 \mathrm{~min}$ ) to remove cell debris. The clear supernatants, the whole lysates and the $0.5 \mathrm{M}-\mathrm{NaCl}$ washings were dialysed (three changes, 21 each) for $18 \mathrm{~h}$ at $4{ }^{\circ} \mathrm{C}$, and assayed for ability to liberate $\mathrm{SO}_{4}^{2-}$ from propan-2-yl sulphate. Under a variety of conditions of substrate concentration, temperature and $\mathrm{pH}$ (see Methods), no release of sulphate from propan-2-yl sulphate was detected.

Some bacterial enzymes, for example the P2 primary alkylsulphatase of Pseudomonas sp. C12B (Fitzgerald, 1974), are known to enjoy only a transient existence during the exponential phase of batch culture. To test this possibility for $P$. syringae GG, bacteria were grown in basal salts/propan-2-yl sulphate on a 10 litre scale. Samples ( 1 litre) were withdrawn at approximately $4 \mathrm{~h}$ intervals, starting in the early exponential phase $(10 \mathrm{~h}$, see Fig. 1) through to early stationary phase $(30 \mathrm{~h})$. Cell extracts were prepared, dialysed and assayed for the ability to liberate sulphate from propan-2-yl sulphate under the same range of conditions of substrate concentration, temperature and $\mathrm{pH}$, but no activity was found.

The search next turned to the culture medium. Several alkylsulphatases are known to be located at the cell periphery (Dodgson et al., 1982) and some have been detected in the culture medium during growth. It was therefore possible that $\boldsymbol{P}$. syringae GG excreted a propan-2-yl sulphate sulphatase into the extracellular medium. To test this possibility, bacteria were grown on propan-2-yl sulphate, and samples collected during growth, as before. Cells were removed by centrifugation and the supernatants concentrated tenfold (Millipore immersible CX-10 membranes), dialysed, and assayed for propan-2-yl sulphate sulphatase. Again, under a variety of conditions of substrate concentration, temperature and $\mathrm{pH}$, no such activity was found. 


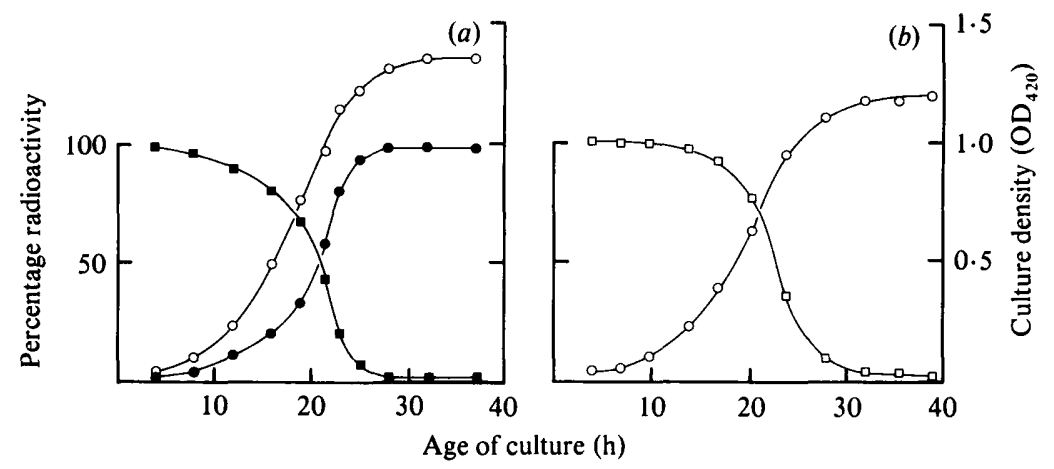

Fig. 2. Utilization of radiolabelled propan-2-yl sulphate during growth of $P$. syringae. Culture OD (O) was measured during growth of $P$. syringae on radiolabelled propan-2-yl sulphate $(0 \cdot 3 \%)$. Cultures contained $(a)$ propan-2-yl $\left[{ }^{35} S\right]$ sulphate $(\square)$, specific activity $0.31 \mathrm{MBq} \mathrm{mmol}^{-1},(b)[1,3-14 \mathrm{C}]$ propan2-yl sulphate $(\square)$, specific activity $0.13 \mathrm{MBq} \mathrm{mmol}^{-1}$. $\bigcirc$, Inorganic sulphate released.

\section{Metabolite production during growth on ${ }^{35} S$ - and ${ }^{14} \mathrm{C}$-labelled propan-2-yl sulphate}

In the absence of a propan-2-yl sulphate sulphatase, the possibility was by now clearly emerging that degradation of the ester was proceeding by a route not initiated by desulphation. A search was therefore made for radioactive metabolites of ${ }^{35} \mathrm{~S}$ - and ${ }^{14} \mathrm{C}$-labelled propan-2-yl sulphate.

Cells were grown in a double phosphate basal salts medium containing unlabelled propan-2-yl sulphate $(0.25 \%)$ and propan-2-yl [ ${ }^{35}$ S] sulphate $\left(0.05 \%, 2.22 \mathrm{kBq} \mathrm{ml}^{-1}\right)$. At intervals during growth, samples were taken and centrifuged to remove cells. Samples $(10 \mu 1)$ of the clear supernatants were examined by TLC in solvent C. Following autoradiography, radioactive areas were scraped from the plate and counted. Growth of the organism was accompanied by a decrease in the amount of ester present in the medium and a corresponding increase in the amount of inorganic sulphate (Fig. 2). No other intermediates containing ${ }^{35} \mathrm{~S}$-label were observed. When the experiment was repeated using [1,3-14 C]propan-2-yl sulphate in place of the ${ }^{35}$ S-labelled compound, the labelled ester disappeared in a similar manner (Fig. 2), and no other ${ }^{14} \mathrm{C}$-labelled compounds could be detected in the medium, the label presumably being either incorporated into cell components or respired as ${ }^{14} \mathrm{CO}_{2}$. While these two experiments clearly showed that propan-2-yl sulphate was utilized during growth, and that liberation of inorganic sulphate was stoicheiometric with disappearance of the ester, the identity of the immediate precursor of $\mathrm{SO}_{4}^{2-}$ was still obscure.

\section{Experiments with resting cell suspensions}

Cells grown in the usual way on propan-2-yl sulphate to mid-exponential or stationary phase were harvested, washed twice in basal salts lacking $\mathrm{NH}_{4} \mathrm{Cl}$ (to minimize further growth) and resuspended in the same medium. The whole cell suspension was divided into two portions which were incubated separately with ${ }^{14} \mathrm{C}$ - or ${ }^{35} \mathrm{~S}$-labelled propan-2-yl sulphate for $24 \mathrm{~h}$. Samples were taken at intervals and examined by TLC and autoradiography. Little degradation had occurred at $6 \mathrm{~h}$, but after $24 \mathrm{~h}$ all the ester had been converted to inorganic sulphate and at no time was there any sign of an intermediate.

\section{Growth on alternative carbon sources}

The absence of a propan-2-yl sulphatase, together with the stoicheiometric accumulation of inorganic sulphate during degradation of propan-2-yl sulphate, clearly implied that the ester was modified in some way before desulphation could take place. The most likely route appeared to be oxidation of one of the methyl groups to produce a primary alcohol. Subsequently, a combination of further oxidation and desulphation (in either order) would liberate lactate. Alternatively both methyl groups could be oxidized to generate glycerol-2-sulphate, and 
combinations of oxidation and desulphation could then give rise to glycerol, glyceraldehyde or glycerate. When some of these compounds were tested separately as growth substrates (propan2-ol at $0.1 \%$ and $0.25 \%$; propan-1,2-diol at $0.25 \%$; DL-lactate at $0.3 \%$; glycerol at $0.2 \%$ ), lactate was much the most effective as a source of carbon and energy for $P$. syringae GG. Clearly a pathway leading to lactate from propan-2-yl sulphate would be sufficient to equip the organism to utilize the ester.

Firm evidence for the involvement of lactate in the metabolism of propan-2-yl sulphate was obtained by growing the organism in a medium containing $\left[1,3-{ }^{14} \mathrm{C}\right]$ propan-2-yl sulphate $(0 \cdot 3 \%$, $\left.10 \mathrm{kBq} \mathrm{ml}^{-1}\right)$ supplemented with either DL-lactate $(1 \%)$ alone or DL-lactate $(1 \%)$ and $\mathrm{Na}_{2} \mathrm{SO}_{4}$ $(0.014 \%)$, or pyruvate $(1 \%)$ and $\mathrm{Na}_{2} \mathrm{SO}_{4}(0.014 \%)$. At $8 \mathrm{~h}$ intervals up to $32 \mathrm{~h}$, samples $(1.5 \mathrm{ml})$ were removed, sonicated for $3 \mathrm{~min}$ to disrupt cells and centrifuged to remove debris before TLC analysis (solvent $\mathrm{C}$ ) in the usual way. In all three cultures, growth occurred mainly at the expense of the major carbon source (lactate or pyruvate), and degradation of propan-2-yl sulphate was evident only in the $24 \mathrm{~h}$ and $32 \mathrm{~h}$ samples. However, these samples from lactate-fortified cultures contained small amounts of a new radioactive spot $\left(R_{F}=0.47\right.$, c.f. propan-2-yl sulphate, $\left.0 \cdot 68\right)$ which was absent from the pyruvate-supplemented medium. Samples containing the new metabolite were pooled and the metabolite was purified by preparative TLC (solvent C). The radioactive band corresponding to the metabolite was scraped off the glass plate and eluted from the silica gel with water. The solution was concentrated by freeze-drying and the residue used to identify the metabolite. In each of the five solvent systems tested (B-F) the metabolite cochromatographed with authentic ${ }^{14} \mathrm{C}$-labelled lactate.

\section{Production of D-lactate-2-sulphatase}

The identification of lactate as an intermediate in the degradation of propan-2-yl sulphate suggested that desulphation might not occur until oxidation of propan-2-yl sulphate had progressed to lactate-2-sulphate. This sequence would require that $P$. syringae grown on propan2-yl sulphate should contain an enzyme capable of desulphating lactate-2-sulphate. Cultures of various composition (nutrient broth, $0.8 \%$, w/v; yeast extract, $0.8 \%, \mathrm{w} / \mathrm{v}$; basal salts containing $1 \%$ pyruvate and $0.014 \% \mathrm{Na}_{2} \mathrm{SO}_{4}$; double phosphate basal salts containing $0.3 \%$ propan-2-yl sulphate, with and without added $\mathrm{Na}_{2} \mathrm{SO}_{4}, 0.014 \%$ ) were inoculated from appropriate starter cultures of $P$. syringae. Cells were harvested in early stationary phase $(24 \mathrm{~h})$ and dialysed extracts were assayed for ability to liberate sulphate from DL-lactate-2-sulphate $(20 \mathrm{mM})$. Lactate-2sulphatase activity was easily measurable in cells grown on media containing propan-2-yl sulphate [0.04 units (mg protein) $\left.{ }^{-1}\right]$, but was absent from all cultures lacking the ester. The presence of added sulphate in the propan-2-yl sulphate cultures had very little effect on the amount of enzyme produced. When the concentration of propan-2-yl sulphate in the growth medium was increased from $0.01 \%$ to $1.0 \%$, specific activity of the enzyme in extracts of stationary phase cells $(46 \mathrm{~h})$ was remarkably constant although the total amount of enzyme increased as a result of higher cell yields. Lactate-2-sulphatase was present at the same specific activity throughout batch culture on $0.3 \%$ propan-2-yl sulphate, from early exponential to late stationary phase. The enzyme has since been purified to homogeneity and characterized as a stereospecific sulphatase acting only on D-lactate-2-sulphate and liberating inorganic sulphate and D-lactate (Crescenzi et al., 1984).

\section{DISCUSSION}

P. syringae GG grew well on propan-2-yl sulphate as sole source of carbon and energy, and growth rates were clearly dependent on the ester concentration (Fig. $1 b$ ). Although the results did not strictly extend into the true exponential phase of growth, values of specific growth rate $(\mu)$ estimated from the earlier time points in Fig. $1 b$ followed the classical (Monod, 1949) hyperbolic dependence on substrate concentration described by the equation $\mu=\mu_{\max } \mathrm{S} /\left(\mathrm{S}+K_{\mathrm{s}}\right)$ where $\mu_{\max }$ is the maximum specific growth rate (occurring at high $\mathrm{S}$ ) and $K_{\mathrm{s}}$ is the substrate saturation constant (characteristic of organism and substrate). From the data in Fig. $1 b, \mu_{\max } \simeq 0.2 \mathrm{~h}^{-1}$ and $K_{\mathrm{s}} \simeq 0.1 \%(\mathrm{w} / \mathrm{v})$. The latter value is high compared with values of 


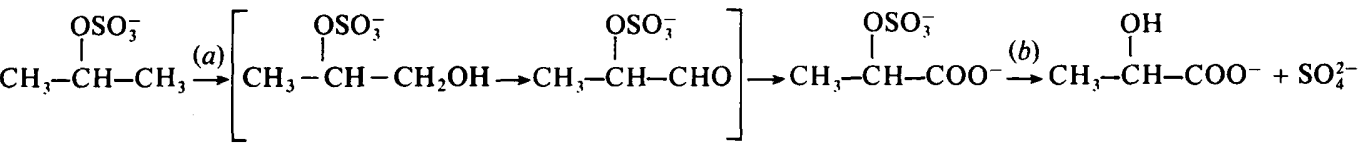

Fig. 3. Proposed pathway for metabolism of propan-2-yl sulphate by $P$. syringae. The absolute specificity of the D-lactate-2-sulphatase $(\operatorname{step} b)$, the absence of a corresponding L-specific enzyme, and the failure of cultures or extracts to accumulate L-lactate-2-sulphate, collectively imply that the initial mono-oxygenation (step $a$ ) is specific for one of the two methyl groups of propan-2-yl sulphate.

$0 \cdot 001-0.010 \%$ generally observed, for example for carbohydrates (Monod, 1949; Bull, 1974). Indeed it is the combination of such low $K_{\mathrm{s}}$ values with substrate concentrations of the order of $\mathrm{g}^{-1}$ that often masks the concentration dependence of growth rates (Bull, 1974). In the present case, the high value of $K_{\mathrm{s}}$ may be attributable partly to the fact that carbon accounts for only onefifth of the mass of the ester $\mathrm{C}_{3} \mathrm{H}_{7} \mathrm{SO}_{4} \mathrm{~K}$. It may also indicate that either an uptake system for propan-2-yl sulphate, or an enzyme involved in the early stages of metabolism (see below) has a high $K_{\mathrm{m}}$ for the ester.

Despite good growth on propan-2-yl sulphate, $P$. syringae GG failed to produce a sulphatase with the appropriate specificity. No activity was detectable either intracellular or extracellular, or at different phases of the batch culture cycle, or using a variety of assay conditions at various substrate concentrations, temperatures and $\mathrm{pH}$ values. The paradox was resolved by the discovery of small amounts of ${ }^{14} \mathrm{C}$-labelled lactate in cultures grown on $\left[1,3-{ }^{14} \mathrm{C}\right]$ propan-2-yl sulphate supplemented with unlabelled lactate. This together with the induction of a stereospecific D-lactate-2-sulphatase in cells grown on propan-2-yl sulphate (Crescenzi et al., 1984) strongly suggested that metabolism of propan-2-yl sulphate proceeded by oxidation of a single methyl group to carboxylate before rapid desulphation to lactate (Fig. 3). Although there is no evidence at present for the intermediate formation of propan-1,2-diol 2-sulphate and lactaldehyde-2-sulphate, their tentative inclusion seems reasonable because a similar stepwise oxidation is known to occur, for example, in the microbial metabolism of methane (Best \& Higgins, 1983) and in the $\omega$-oxidation of alkanes (Ratledge, 1978). The scheme depicted in Fig. 3 contrasts with the routes for the microbial degradation of simple alkyl sulphates and choline sulphate which are usually considered to begin with a desulphation step (Dodgson et al., 1982). However, the oxidation-desulphation sequence, although unusual, is not entirely without precedent. Thus, $P$. fluorescens (NCIB 8248) is able to utilize D-glucose 6-sulphate, as sole source of carbon and sulphur, in an analogous way. The ester, when serving only as sole source of sulphur was first oxidized to D-gluconate 6-sulphate before enzymic liberation of sulphate. Cell extracts were able to liberate the sulphate needed for growth from D-gluconate 6-sulphate but not from the parent D-glucose 6-sulphate (Fitzgerald \& Dodgson, $1971 b$ ). Moreover, when D-glucose 6-sulphate served as source of both carbon and sulphur, metabolism of the D-gluconate 6sulphate continued along the Entner-Doudoroff pathway to D-glycerate 3-sulphate. Cell extracts contained enzyme(s) capable of desulphating both D-gluconate 6-sulphate and Dglycerate 3-sulphate but not the parent ester (Fitzgerald \& Dodgson, 1971a).

An intriguing feature of the steps leading from symmetrical propan-2-yl sulphate to the liberation of inorganic sulphate and D-lactate is their stereochemistry. Propan-2-yl sulphate is prochiral and oxidation of its enantiotopic methyl groups could lead, in principle, to either D- or L- or DL-lactate-2-sulphate. However, the D-lactate-2-sulphatase produced by $P$. syringae grown on propan-2-yl sulphate was absolutely stereospecific, both in its requirement for the D-substrate and in its production of D-lactate. If $P$. syringae was able to convert propan-2-yl sulphate to Llactate-2-sulphate, the latter should accumulate in cultures because it is not hydrolysed by the Dlactate-2-sulphatase. In fact no such accumulation occurred during degradation of propan-2-yl sulphate, implying either that L-lactate-2-sulphate was not formed in the first instance, or that possibly a racemase was present that inverted the L-isomer to the D-form. Previous work (Crescenzi et al., 1984) has shown that crude cell-extracts of $P$. syringae GG grown on propan-2- 
yl sulphate (and so containing D-lactate-2-sulphatase) hydrolysed only $50 \%$ of DL-lactate-2sulphate. A racemase capable of interconverting $L-$ and D-isomers was clearly absent. It thus appeared that L-lactate-2-sulphate was never present, and the collective evidence strongly suggests that oxidation of propan-2-yl sulphate was stereospecific leading only to D-lactate-2sulphate. Stereospecificity of this type among mono-oxygenases appears not to have been reported hitherto, and would seem to offer an interesting avenue for future work and to hold potential for industrial exploitation in the production of optically active compounds.

The bacterial alkylsulphatases studied hitherto (Dodgson et al., 1982; Dodgson \& White, 1983; Dodgson et al., 1984) that initiate degradation of simple primary and secondary alkyl sulphate esters, fail to operate on esters of chain length less than $C_{5}$. Shorter-chain alkyl sulphates have been identified in a variety of sources, both natural and anthropogenic, but they appear not to accumulate in large quantities in the environment. Evidently biodegradation routes other than simple desulphation must be involved and the present paper has identified one of them. It now remains to be seen whether microbial degradation of other short-chain alkyl sulphates (e.g. methyl, ethyl, $n$-propyl, and $n$ - and iso-butyl sulphates) is accomplished by a similar combination of oxidation and desulphation, or whether further novel pathways are involved. Work on degradation of these compounds is currently in progress in our laboratories.

We thank the Department of Chemistry, University College Cardiff for performing the $\mathrm{C}$ and $\mathrm{H}$ analysis and NMR spectroscopy, and Dr A. Tatevossian, Department of Physiology, University College Cardiff, for the gift of $[1-1+C]$ lactate.

\section{REFERENCES}

Barrett, C. H., Dodgson, K. S. \& White, G. F (1980). Preliminary observations on alcohol dehydrogenases in Comamonas terrigena that exhibit stereospecificity towards secondary alcohols. Biochemical Journal 187, 703-709.

Barrett, C. H., Dodgson, K. S. \& White, G. F. (1981). Specificity and other properties of an alcohol dehydrogenase purified from Comamonas terrigena. An enzyme exhibiting specificity for L-stereoisomers of secondary alcohols. Biochimica et biophysica acta 661, 74-86.

Bartholomew, B., Dodgson, K. S. \& Gorham, S. D. (1978). Purification and properties of the S1 secondary alkylsulphohydrolase of the detergentdegrading micro-organism, Pseudomonas C12B. Biochemical Journal 169, 659-667.

Best, D. J. \& Higgins, I. J. (1983). Methane-utilising organisms (methanotrophs) as biocatalysts. In Topics in Enzyme and Fermentation Biotechnology, vol. 7, pp. 38-75. Edited by A. Wiseman. Chichester: Ellis Horwood.

Bull, A. T. (1974). Microbial growth. In Companion to Biochemistry, pp. 415-442. Edited by A. T. Bull, J. R. Lagnado, J. O. Thomas \& K. F. Tipton. London: Longman.

Cloves, J. M., Dodgson, K. S., White, G. F. \& Fitzgerald, J. W. (1980). Purification and properties of the P2 primary alkylsulphohydrolase of the detergent-degrading bacterium Pseudomonas C12B. Biochemical Journal 185, 23-31.

Crescenzi, A. M. V., Dodgson, K. S. \& White, G. F. (1984). Purification and some properties of D-lactate2-sulphatase of Pseudomonas syringae GG. Biochemical Journal 223, 487-494.

Denner, W. H. B., Olavesen, A. H., Powell, G. M. \& Dodgson, K. S. (1969). The metabolism of potassium dodecyl $\left[{ }^{35}\right.$ S]sulphate in the rat. Biochemical Journal 111, 43-51.
Dodgson, K. S. (1961). Determination of inorganic sulphate in studies on the enzymic and non-enzymic hydrolysis of carbohydrate and other sulphate esters. Biochemical Journal 78, 312-319.

DodGson, K. S. \& WhITE, G. F. (1983). Some enzymes involved in the microbial degradation of sulphated surfactants. In Topics in Enzyme and Fermentation Biotechnology. vol. 7, pp. 90-155. Edited by A. Wiseman. Chichester: Ellis Horwood.

Dodgson, K. S., White, G. F. \& Fitzgerald, J. W. (1982). Sulfatases of Microbial Origin, vols 1 \& 2. Boca Raton: CRC Press.

Dodgson, K. S., White, G. F., Massey, J. A., Shapleigh, J. \& PaYNe, W. J. (1984). Utilization of sodium dodecyl sulphate by denitrifying bacteria under anaerobic conditions. FEMS Microbiology Letters 24, 53-56.

DoudorofF, M. \& Palleroni, N. J. (1974). In Bergey's Manual of Determinative Bacteriology, 8th edn., pp. 217-243. Edited by R. E. Buchanan \& N. E. Gibbons. Baltimore: Williams and Wilkins.

Fitzgerald, J. W. (1974). Hydrolysis of sodium hexan-I-yl sulphate by the P2 electrophoretic form of primary alkylsulphatase. Microbios 11, 153-158.

FitzGerald, J. W. \& Dodgson, K. S. (1971 a). Sulphur utilization during growth of Pseudomonas fluorescens on potassium D-glucose 6-O-sulphate. Biochemical Journal 121, 521-530.

Fitzgerald, J. W. \& Dodgson, K. S. (1971 b). Carbon and sulphur utilization during growth of Pseudomonas fluorescens on potassium D-glucose-6- $O$-sulphate as the sole sulphur source. Biochemical Journal 122, 277-283.

LeE, M. L., LATER, D. W., Rollins, D. K., Eatough, D. J. \& HANSEN, L. D. (1980). Dimethyl and monomethyl sulfate: presence in coal fly ash and airborne particulate matter. Science 207, 186-188.

Lijmbach, G. W. M. \& BRinkHuIS, E. (1973). 
Microbial degradation of secondary $n$-alkyl sulfates and secondary alkanols. Antonie van Leeuwenhoek 39, 415-423.

Lloyd, A. G., Tudball, N. \& Dodgson, K. S. (1961). Infra red studies on sulphate esters. III. $O$-Sulphate esters of alcohols, amino alcohols and hydroxylated amino acids. Biochimica et biophysica acta 52, 413419.

Maggs, J. L., Powell, G. M., Dodgson, K. S., Howes, D., Black, J. G. \& Olavesen, A. H. (1982). Metabolism in the rat of potassium DL-octan-2sulphate, a secondary alkyl sulphate. Xenobiotica 12, 101-109.

Maggs, J. L., Powell, G. M., Olavesen, A. H. \& CurTIS, C. G. (1984). Octan-2-sulphate degradation in the isolated perfused rat liver. Biochemical Pharmacology 33, 827-829

Matcham, G. W. J., Dodgson, K. S. \& Fitzgerald, J. W. (1977). Purification, properties and cellular localization of the stereospecific CS2 secondary alkylsulphohydrolase of Comamonas terrigena. Biochemical Journal 167, 723-729.

MONOD, J. (1949). The growth of bacterial cultures. Annual Review of Microbiology 3, 371-394.

RATLEDGE, C. (1978). Degradation of aliphatic hydro- carbons. Developments in the Biodegradation of Hydrocarbons 1, 1-46.

Shaw, D. J., Dodgson, K. S. \& White, G. F. (1980). Substrate specificity and other properties of the inducible S3 secondary alkylsulphohydrolase purified from the detergent-degrading bacterium Pseudomonas C12B. Biochemical Journal 187, 181196.

Thomas, J. H. \& Tudball, N. (1967). Studies on the enzymic degradation of $L$-serine- $O$-sulphate by a rat liver preparation. Biochemical Journal 105, 467-472.

White, G. F., Lillis, V. \& Shaw, D. J. (1980). An improved procedure for the preparation of alkyl sulphate esters suitable for the study of secondary alkylsulphohydrolase enzymes. Biochemical Journal 187, 191-196.

White, G. F., Russell, N. J. \& DAY, M. J. (1984). A survey of sodium dodecyl sulphate (SDS) resistance and alkylsulphatase production in bacteria from clean and polluted river sites. Environmental Pollution A37, 1-11.

YAGI, T. (1964). Isopropyl sulfuric acid in chick embryos. Biochimica et biophysica acta 82, 170-172.

YAGI, T. (1966). Sulfate esters in developing eggs. Journal of Biochemistry, Tokyo 59, 495-500. 